\title{
Teaching the Genome Generation: Bringing Modern Human Genetics into the Classroom Through Teacher Professional Development
}

\author{
Kelly M. LaRue ${ }^{1}$, Michael P. McKernan'1 Kristin M. Bass², and Charles G. Wray ${ }^{1}$ \\ ${ }^{1}$ Genomic Education, The Jackson Laboratory, Bar Harbor, ME, ${ }^{2}$ Rockman et al., San Francisco, CA \\ DOI: 10.15695/jso.v1i2.4552 \\ Keywords: Genomics, Genetics, Laboratory, Bioethics, Bioinformatics, Professional Development, Teacher, High School \\ DOI: https://doi.org/10.15695/jstem/v1i1.12
}

\begin{abstract}
Teaching the Genome Generation (TtGG) is a teacher professional development program and set of high school biology lessons that support interwoven classroom instruction of molecular genetics, bioinformatics, and bioethics. Participating teachers from across New England implement the modular elements of program at a high rate in a variety of biology classrooms. Evaluation data collected over three academic years (2014/15 to 2016/17) indicate that TtGG has increased teachers' abilities to integrate complex concepts of genomics and bioethics into their high school classes.
\end{abstract}

\section{INTRODUCTION}

Since the completion of the human genome, our understanding of genetic variation has exploded. Not a month goes by without the publication of new genomes, expansion of genomic databases, discovery of rare disease-causing variations or reports of drug efficacy-genotype associations. The lay-media regularly cover genomics-driven ethical issues or the promises of genomic medicine. Direct-to-consumer genetic testing companies such as 23 andMe and Ancestry.com now use mass-market television campaigns to advertise their services. Genomics has ever-increasing relevance to everyday life.

The biological details of genomics can be overwhelming for learners at any level. Unlike genetics, which considers a single or a few genes at a time, the study of genomics considers all variants, genes and chromosomes across the genome simultaneously. However, many genomic concepts are well within the capabilities and scope of general secondary school biology education. Unfortunately, few teachers have previously received genomics training or any guidance in how to teach the subject to their students. Even those who have been trained in genetics face a daunting challenge: genomic data and knowledge are expanding so rapidly that it is nearly impossible for teachers to stay current given their other responsibilities (Wray, 2017). Though it is difficult to keep pace with the changing face of genomics research, it is extremely valuable for teachers to refresh their knowledge and embed genomics content into lesson plans whenever possible.

In their review of genomic medicine ten years after the human genome sequence was released, Green and Guyer (2011) emphasized that education of everyone from doctors to patients will be critical for the successful integration of genomics into healthcare. Therefore, secondary school teachers are poised to have a great impact on increasing public genomic literacy. Additionally, the ethical and legal debates unfolding in the genomics era (Middleton et al., 2015) offer students an opportunity to discuss the far-reaching social implications of genomic science. It has been shown that high school teachers who introduce their students to careers and real-world issues increase student likelihood to enroll in STEM classes and pursue STEM majors in college (Maltese and Tai, 2010).

Teaching the Genome Generation (TtGG) is a high school teacher professional development (PD) program that provides educators in the New England region with the tools they need to prepare their students for life in the genomics era. The program is operated by The Jackson Laboratory (JAX), a non-profit biological research institution, and is funded by an NIH Science Education Partnership Award (SEPA, R25-GM129169). JAX TtGG staff, with partners from the SEPA-funded Personal Genetics Education Project (pgEd, Harvard Medical School), deliver a summer pro- 
fessional development course that integrates instruction in molecular genetics laboratory techniques, bioinformatics and bioethics. The three components of the program are woven into a series of lessons that celebrate human genetic diversity and promote understanding of genomic medicine. Teachers are empowered to utilize the modular lessons in their own classrooms through extensive post-course support and mutual partnerships (Moreno, 2005). During the school year, the TtGG program provides teachers with customized mobile laboratory kits, extensive curriculum resources and access to a 24/7 Genomics Help Desk.

Here we present preliminary outcomes and findings of the TtGG program after four years of summer professional development courses and three years of supporting classroom implementation. We report on how teacher training needs have changed and how our teacher-participants are integrating the program into their established courses. Finally, we describe our vision for the future of this program and the evolving needs of genomics education in high school classrooms.

\section{PROGRAM COMPONENTS}

Professional Development Course. Residential teacher professional development (PD) courses are an essential activity of the TtGG program. We engage up to 32 teachers per year in approximately 40 hours of in-person training. TtGG covers the cost of the program, including travel and subsistence, and all participants earn a $\$ 500$ stipend.

The summer PD courses address learning objectives across three topical areas: molecular genetics; bioinformatic;, and ethical, legal and social issues (ELSI) in genomics. About $40 \%$ of the five-day, 40 -hour course is spent in the laboratory with hands-on training in molecular genetics where teachers practice techniques and methods employed in the study of human genetic variation. During the remainder of the course, equal time ( $\sim 30 \%$ each) is spent on bioethics discussions and instruction in bioinformatics. The instructional model is multi-disciplinary and includes lessons in all three topical components each day. For instance, a course day will include molecular biology lab work on a gene linked to human athletic performance, followed by ethics discussions on the marketing of direct-to-consumer genetic tests targeting student athletes, and concluding with training in DNA sequence analysis and genetics databases.

Along with skills development and content instruction, the PD course sets aside a substantial amount of time for discussion of pedagogy and lesson plan development. On the last day of the course, teachers start to plan their academic year implementation with TtGG staff support, and in consultation with peers. The modularized nature of the TtGG content allows teachers the flexibility to choose a pathway of lessons that is matched to their classroom needs (Figure 1). All lessons are mapped to Next Generation Science Standards (NGSS) and AP Biology standards (Table 1) to assist in module selection and fluid integration of TtGG into established high school curricula.

All PD materials (paper and digital) are designed and formatted for usability with high school students in consultation with practicing teachers and graphic designers. We create two versions of each lesson or protocol. The student versions contain procedural steps, content questions and white space for taking notes. The teacher versions are identical in process but also include answers to posed questions, timing considerations, sample storage notes, technical explanations, etc.

We describe the three topical components of the TtGG teacher PD course more thoroughly below:

Molecular Genetics. The molecular genetics arm of the program demonstrates human genetic variation through six

Table 1. TtGG content alignment to secondary school standards.

NGSS Alignment AP Biology Alignment

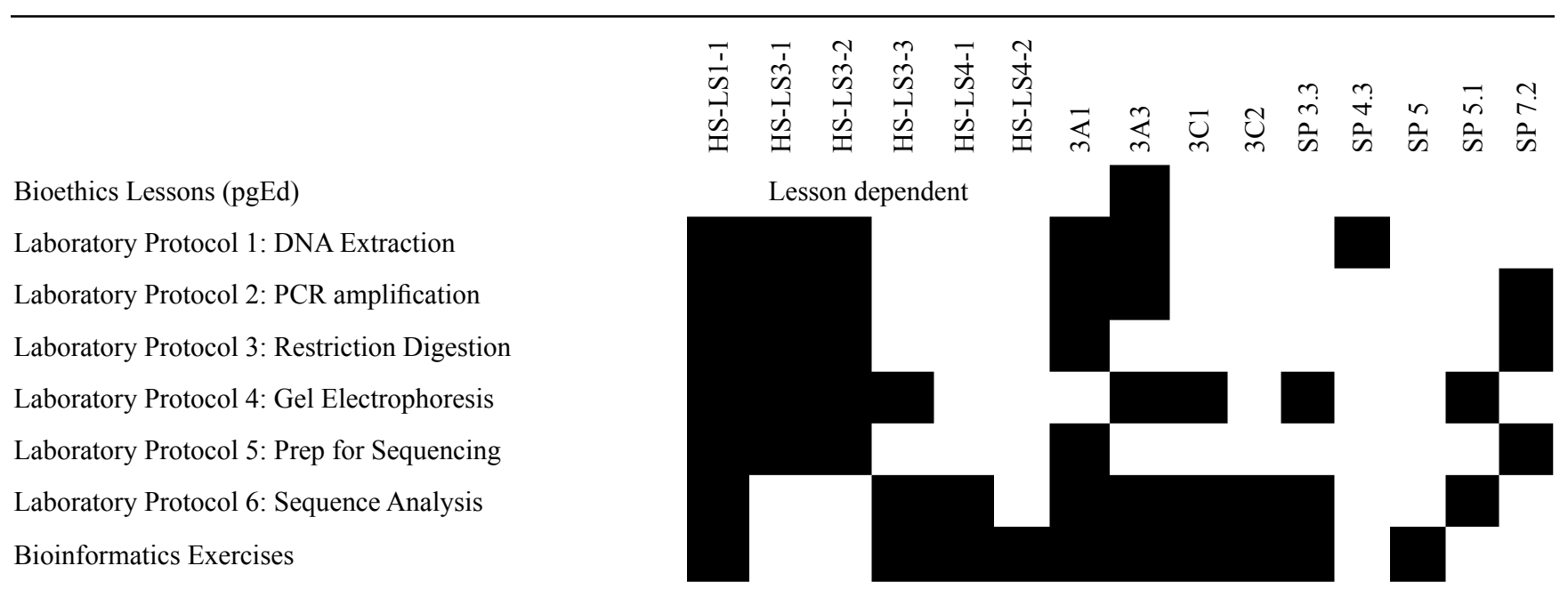




\section{TtGG PROGRAM OPTIONS}

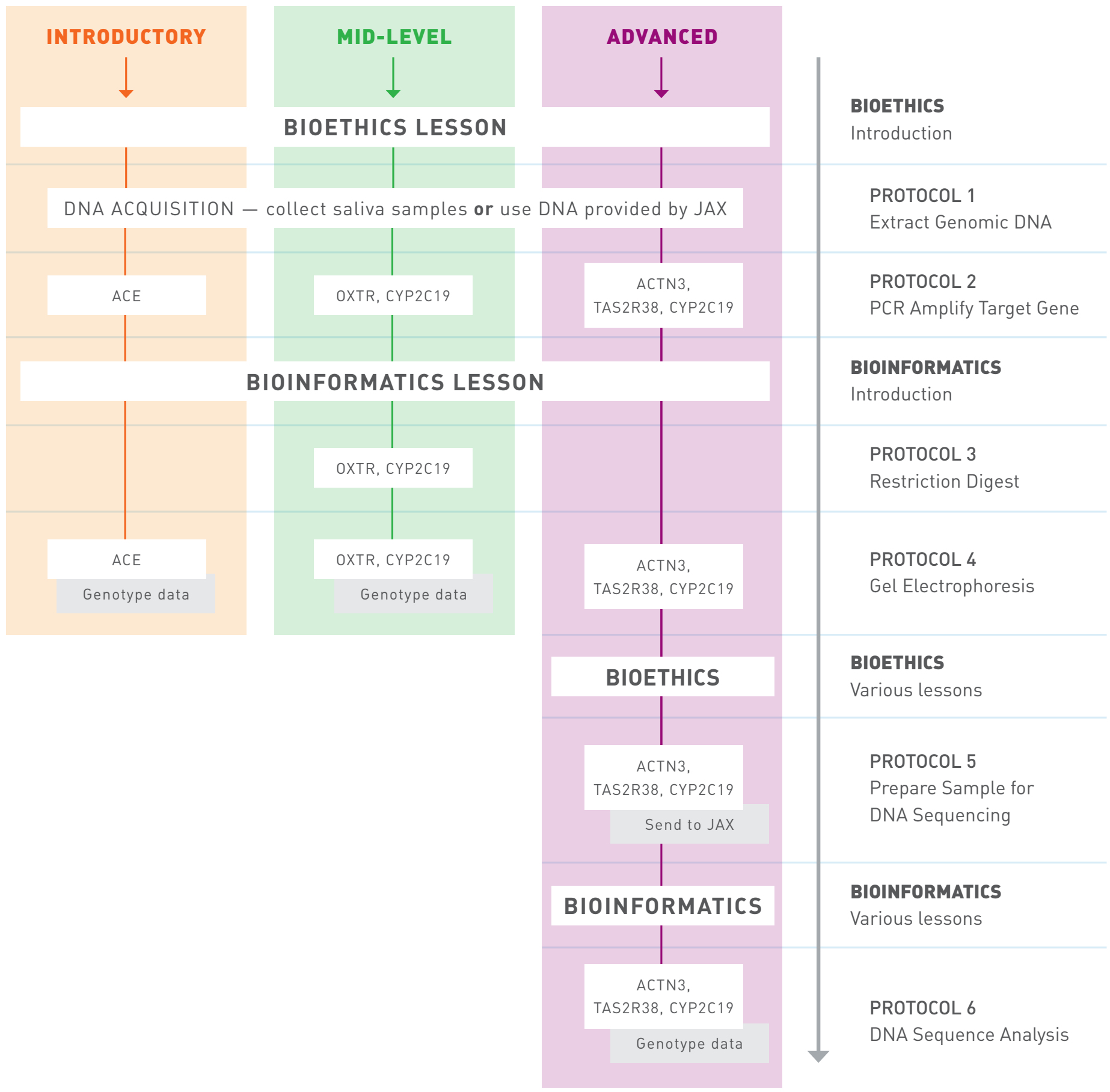

Figure 1. TtGG Lesson Offerings for Biology Teachers. The right-most column identifies the program category or protocol used with students by row. Options within rows represent lessons or exercises that teachers can select for implementation. The three dominant pathways implemented by teachers are displayed in colored vertical columns and are differentiated by recommended instructional level. Teachers follow the pathways along the vertical workflow from top to bottom. While most teachers follow the recommended pathways, lesson selection is completely customizable. Teachers commonly choose a pathway of cohesive bioethics lessons, laboratory assays and bioinformatics to satisfy the learning needs or grade band of their students. 
molecular assays. We selected and designed the assays to 1) engage interest in human genetics and precision medicine, 2) demonstrate different types of genomic sequence variation (Table 2), and 3) teach a variety of laboratory techniques (Figure 1).

The TtGG sequence of lessons begins with anonymous sampling and isolation of participant genomic DNA for use in subsequent genotyping demonstrations. TtGG uses human DNA because it has been shown in both undergraduate and medical student genomics education that use of personal samples and data can serve as a valuable method for engagement and learning (Salari et al., 2013; Weber et al., 2015; Garber et al., 2016). We have selected five genetic loci that are highly variant in human populations and are not currently associated with a disease phenotype (Table 2).

In our lessons, saliva samples are collected from students and DNA extracted by either cell lysis (miniPCR Xtract buffer) or ethanol precipitation (DNAGenotek Oragene 500). During DNA extraction samples are transferred into unmarked microcentrifuge tubes which are shuffled by an instructor, labeled with an alphanumeric code, and randomly redistributed to students. In this way, TtGG enhances the personal connection to the laboratory demonstration (by use of human, particularly classmate, DNA), while maintaining participant privacy and confidentiality. While ensuring sample anonymity can leave some students feeling dissatisfied as they do not get to know their individual results, our ob- servations and previous studies suggest that students more deeply engage with this participatory model of learning rather than providing samples of prepared DNA. Additionally, it serves as a perfect context for lessons on genomic privacy, confidentiality, and the differences between laboratory demonstrations and clinical assays (see Bioethics, below).

Once genomic DNA has been isolated, teachers can choose subsequent activities from a series of pathways that best fit their curricular needs, academic schedule, and the rigor of the course in which TtGG lessons are taught. This modularization allows TtGG to be taught across many grade bands, in different life science courses (Introductory to AP biology), and allows for instructor customization. The pathways, summarized below, are described in the TtGG curriculum and practiced during the in-person short course.

During the PD course, teachers determine genotypes of anonymous DNAs by polymerase chain reaction (PCR) amplification using RedTaq ReadyMix (Sigma-Aldrich, Inc.), custom primers (Integrated DNA Technologies, Inc.) and reconditioned T-100 (Bio-Rad Laboratories, Inc.) or miniPCR (miniPCR Ampylus) thermal cyclers and subsequent procedures. Teachers of introductory courses are encouraged to use the Angiotensin Converting Enzyme I (ACE) module which tests for presence or absence of an Alu insertion within an intron of the ACE gene. In this case, only post-PCR gel electrophoresis (FlashGel System, Lonza) is necessary for genotype analysis due to fragment length differences in the

Table 2. Description of human loci assayed in TtGG.

\begin{tabular}{|c|c|c|c|c|c|}
\hline Gene name & $\begin{array}{c}\text { Gene } \\
\text { Symbol }\end{array}$ & $\begin{array}{c}\text { Description of variant } \\
\text { assayed }\end{array}$ & Link to Humans & Reference & Link to ELSI topics \\
\hline $\begin{array}{l}\text { Cytochrome } \\
\text { P-450, family } \\
\text { 2, subfamily C, } \\
\text { polypeptide } 19\end{array}$ & CYP2C19 & $\begin{array}{l}\text { Aberrant splice site, } \\
\text { eliminates } 40 \mathrm{bp} \text {. Loss of } \\
\text { protein function. }\end{array}$ & $\begin{array}{l}\text { Associated with defec- } \\
\text { tive drug metabolism. }\end{array}$ & $\begin{array}{l}\text { Goldstein and Blais- } \\
\text { dell, } 1996\end{array}$ & Ethics and Personalized Genetics \\
\hline $\begin{array}{c}\text { Taste } 2 \text { Receptor } \\
\text { Member } 38\end{array}$ & $T A S 2 R 38$ & $\begin{array}{l}\text { Polyallelic variation with- } \\
\text { in one gene. }\end{array}$ & $\begin{array}{l}\text { Impacts ability to taste } \\
\text { bitter compounds, PTC. }\end{array}$ & Kim et al. 2003 & \\
\hline Alpha Actinin 3 & $A C T N 3$ & $\begin{array}{l}\text { Nonsense mutation, } \\
\text { premature stop codon } \\
(\mathrm{R} 577 \mathrm{X}) .\end{array}$ & $\begin{array}{l}\text { Association with } \\
\text { improved athletic } \\
\text { performance in events } \\
\text { involving fast twitch } \\
\text { muscle }\end{array}$ & Yang et al., 2003 & $\begin{array}{l}\text { Athletic Performance, Genetic Com- } \\
\text { plexity and Ethics }\end{array}$ \\
\hline $\begin{array}{l}\text { Angiotensin } \\
\text { I Converting } \\
\text { Enzyme }\end{array}$ & $A C E$ & $\begin{array}{l}\text { Insertion of Alu repeat } \\
\text { within intron } 16 .\end{array}$ & $\begin{array}{l}\text { Associated with im- } \\
\text { proved endurance in } \\
\text { long distance events }\end{array}$ & $\begin{array}{l}\text { Puthucheary et al. } \\
2011\end{array}$ & \\
\hline $\begin{array}{l}\text { Oxytocin Re- } \\
\text { ceptor }\end{array}$ & OXTR & $\begin{array}{l}\text { SNP within intron, silent } \\
\text { mutation. No protein } \\
\text { effect. }\end{array}$ & $\begin{array}{l}\text { Associated with human } \\
\text { social behaviors. }\end{array}$ & $\begin{array}{l}\text { Kumsta and Hein- } \\
\text { richs, } 2013\end{array}$ & $\begin{array}{l}\text { Genetics, Behavior and Criminal } \\
\text { Activity }\end{array}$ \\
\hline
\end{tabular}


PCR products (Figure 1, orange pathway). By comparison, we recommend that Honors or AP courses complete modules that require downstream enzymatic processing of PCR products: the Oxytocin Receptor (OXTR) and Cytochrome P450 (CYP2C19) modules include genotyping by restriction enzyme digest (digested by BamHI and SmaI, respectively, New England Biolabs, Inc.) and subsequent gel electrophoresis (Figure 1, green pathway). Instructors for AP or elective genetics courses may choose to determine the genotype through an even more advanced assay for $\alpha$-Actinin 3 (ACTN3) and Taste Receptor 2 member 38 (TAS2R38). Genotypes for these loci (along with CYP2C19) are determined by sequencing with the Sanger chain termination method. In these assays, PCR products are prepared for sequencing by enzymatic digestion with ExoSAP-IT (Affymetrix, Thermo Fisher Scientific, Inc.). The JAX Sanger Sequencing Core performs the sequencing and returns chromatograph files that are then analyzed by FourPeaks, Chromas or Benchling software depending on the operating/hardware systems used at each school (Figure 1, purple pathway). See Table 2 for more details on these genetic assays.

During the PD course, teachers complete all five possible genetic assays using the same equipment, reagents and plastic consumables that can be provided to them during the academic year (Table 3). Materials were selected for ease of use, time efficiency and affordability. At the end of the
PD, teachers work with TtGG staff to select or customize laboratory pathways and schedule their academic year implementation.

Bioinformatics. Bioinformatics exercises are built to reinforce content in the laboratory exercises and highlight deep levels of DNA sequence variation in the human genome. For a majority of teachers, TtGG is an introduction to the wealth of publicly accessible online genetic and genomic resources. Teachers are introduced to genomic databases and learn practical skills such as PCR primer design and DNA sequence analysis. Bioinformatics skills are used to analyze data from the molecular genetics arm and can be applied to classroom projects outside of the TtGG program.

We currently offer five exercises that help teachers and students alike perform genetic data analysis and explore the enormous amount of genomic data available online. Exercise \#1 is an introduction to NCBI Gene (www.ncbi.nlm.nih. gov/gene), and Online Mendelian Inheritance in Man (www. omim.org), and highlights genomic regions and transcripts from human genes. Participants choose from a list of genes associated with familiar diseases (e.g. cancer, BRCA1; Huntington's, HTT; cystic fibrosis, CFTR) and investigate how the gene is reported within the database. Exercise \#2 introduces the UCSC (genome.ucsc.edu) and Ensembl (www. ensembl.org) genome browsers. The exercise introduces transcripts, SNPs, and the tens of thousands of known vari-

Table 3. Mobile laboratory kit equipment and consumable contents

\begin{tabular}{|c|c|c|}
\hline Item & Recommended Vendor & Approximate Price \\
\hline Dry bath and block & USA Scientific & $\$ 450$ \\
\hline Centrifuge ( $1.5 \mathrm{~mL}$ tubes $)^{*}$ & Eppendorf & $\$ 1,700$ \\
\hline Centrifuge $(0.2 \mathrm{~mL}$ tubes $)$ & USA Scientific & $\$ 30$ \\
\hline $\begin{array}{l}\text { Reconditioned thermal cycler (96 wells) or } \\
\text { miniPCR ( } 8 \text { wells)* }\end{array}$ & Bio-Rad or miniPCR & $\$ 2,000$ or $\$ 600$ \\
\hline Vortex & Cambridge Scientific & $\$ 175$ \\
\hline Micropipettors (P20, 200 and 1000)* & miniPCR & $\$ 150$ (per set) \\
\hline Gel electrophoresis system* & Lonza/VWR & $\$ 1,700$ \\
\hline Micropipettor tips (P20, 200 and 1000)* & USA Scientific & $\$ 65$ each (box of 10$)$ \\
\hline Tubes $(1.5 \mathrm{~mL})^{*}$ & USA Scientific & $\$ 20($ bag of 500$)$ \\
\hline Tubes $(0.2 \mathrm{~mL})^{*}$ & USA Scientific & $\$ 80($ box of 1000$)$ \\
\hline Laptop (Windows) & variable & \\
\hline Tube racks $(1.5 \text { and } 0.2 \mathrm{~mL})^{*}$ & USA Scientific & $\$ 30($ pack of 7$)$ \\
\hline Labtop cooler & Nalgene & $\$ 30($ pack of 5$)$ \\
\hline Wash bottle & Fisher Scientific & $\$ 55$ (pack of 6) \\
\hline Fine-tip laboratory pens & Sharpie & $\$ 8($ pack of 12$)$ \\
\hline
\end{tabular}


ants that have been described in the CFTR gene. Exercise \#3 trains participants to use BLAST (www.ncbi.nlm.nih.gov/) and CLUSTAL (www.ebi.ac.uk/tools/msa/clustalo) to align and compare sequences from mammals. Participants use BLAST to download and analyze the CYP2C19 and ACTN3 sequencing reactions done in the laboratory. Exercise \#4 requires learners to design primers using the NCBI Gene database and the IDT PrimerQuest Tool (www.idtdna.com/ primerquest), which helps teachers identify a target genomic region and design PCR primers for targeted DNA amplification. Exercise \#5 is a guided lesson on in silico PCR and includes a computer simulated TtGG genotyping assay using the UCSC Genome Browser in silico PCR tool (rohsdb.cmb. usc.edu/GBshape/cgi-bin/hgPcr) and the NEBcutter tools (nc2.neb.com/NEBcutter2).

Bioethics Lessons. Bioethics lessons, derived from the Personal Genetics Education Project (pgEd), align with and support the molecular genetics arm of the program. There are six ethics lessons during the PD course that utilize active learning strategies to explore topics including the genetics of athleticism (with a focus on ACTN3), reproduction (including prenatal genetic screening), aggression and human behavior, the American eugenics movement, and the future of genetic engineering (including CRISPR and similar technologies). Bioethics lessons during the PD course model how to introduce and facilitate discussion on controversial and sometimes difficult subjects with high school students. The lessons encourage teachers, and subsequently students, to see multiple perspectives on complex ethical, legal and social issues in genetics and aid in solidifying key concepts from the molecular genetics and bioinformatics modules. Teachers wishing to expand their instruction of ethical, legal, and social issues in genomics can access additional comprehensive lessons on the pgEd website (www.pged.org,) which can be customized to fit teacher and classroom needs.

Academic Year Support. Following summer professional development, Teaching the Genome Generation supports trained teachers during the academic year. Teachers are provided continual access to updated genomics education resources through an online TtGG repository including laboratory protocols, bioethics and bioinformatics exercises, TtGG-produced instructional videos and external content including news articles, abstracts of scientific papers, and suggested books.

While online 'evergreen' content helps to sustain and extend professional development, the goals of TtGG are best expressed when students complete laboratory exercises using JAX-provided supplies and equipment. Upon completion of the PD course, teachers can schedule delivery of a TtGG mobile laboratory kit for two weeks during the school year. Mobile laboratory kits are outfitted with all of the equipment and consumables used in the summer PD course
(Table 3 ) and individually aliquotted reagents customized for class size and genetic assay(s) selected. Kits are standalone laboratories and require only electricity and a freezer to complete all TtGG lessons. Kits are disseminated from The Jackson Laboratory campuses in Bar Harbor, Maine and Farmington, Connecticut.

During the academic year, frequent contact is maintained (at least once monthly) with teachers as they integrate genomics lessons into their classes and teaching laboratories. When the mobile laboratory is on-site at the school, teachers have unlimited access to a Genomics Help Desk, through which they may contact TtGG staff to answer technical questions or assist in planning. Peer Implementation Coordinators, who are experienced alumni and champions of the TtGG program, provide additional on-the-ground support and pedagogical assistance in both Connecticut and Maine.

While extensive support is provided to teachers during the academic year, the goal is to have teachers independently implement the TtGG lessons. The team (including Peer Implementation Coordinators) does not enter a classroom unless requested. Even when requested, a designated staff member will visit only for a single day. The team recognizes and respects the autonomy of high school teachers and trusts that through effective PD and support, teachers will select and implement TtGG lessons to fit their instructional needs. This approach promotes independence and builds confidence in TtGG implementation through obligatory self-reliant practice.

\section{PRELIMINARY EVALUATION OF TTGG}

The TtGG program is built upon two goals: 1) increase participating teachers' abilities to integrate complex concepts of genomics and bioethics into their high school classes; and 2) increase student understanding of genetics, genomics and bioethics and, through positive exposure to TtGG content, energize students to enroll in future STEM courses. To achieve these goals, the TtGG program expands the focus of genetics education beyond a discussion of Mendelian principles and engages teachers and their students in experiences that explore concepts in genomics. While abundant anecdotal and preliminary evidence exists to support the hypothesis that TtGG leads to enhanced genomics education, a multi-faceted evaluation plan is being used to measure program outcomes.

\section{Professional Development Course Provides Skills Train-} ing for Teachers. Between 2014 and 2017, 111 teachers attended a TtGG in-residence professional development course at one of two sites (Bar Harbor, ME or Hartford, CT) (see Figure 2A). Enrollment is open to all high school teachers (with preference given to teachers from underserved rural and urban schools) and the program is growing rapidly through a grassroots word-of-mouth network of participants. 
Only a handful of teachers per year attend the course due to a district-targeted invitation. A majority of teachers were employed in high schools (97/111, Figure 2B) or public schools (91/111, Figure 2C). We have reached a total of 93 schools, including 17 where more than $20 \%$ of the students are members of groups underrepresented in science, and 39 where more than $20 \%$ of the students receive free lunch. 2014 was considered a pilot year and data beyond participant demographics was not collected.

Pre-course knowledge. Beginning in 2015, we used the Genetics Literacy Assessment Instrument (GLAI, Bowling et al. 2008) to assess teacher genetics content knowledge prior to the professional development course. We administered 23 out of 30 questions from the GLAI using the Qualtrics ${ }^{\circledR}$ Research Suite. All GLAI sub-concepts were addressed with the exception of Transmission. Teachers scored very well in this assessment over all cohorts and years, averaging a $92.5 \pm 6.5 \%$ correct response rate on all items (data not shown). There was not a significant difference in scores between individual cohorts or grouped Maine and Connecticut cohorts (Two-way ANOVA, by cohort: $\mathrm{F}(5,115)=1.41$, $\mathrm{p}=$ .225 ; by state: $\mathrm{F}(1,23)=1.89, \mathrm{p}=.182)$, however there was some variation across items. Considering the GLAI is built as an assessment for undergraduates and is generally aligned

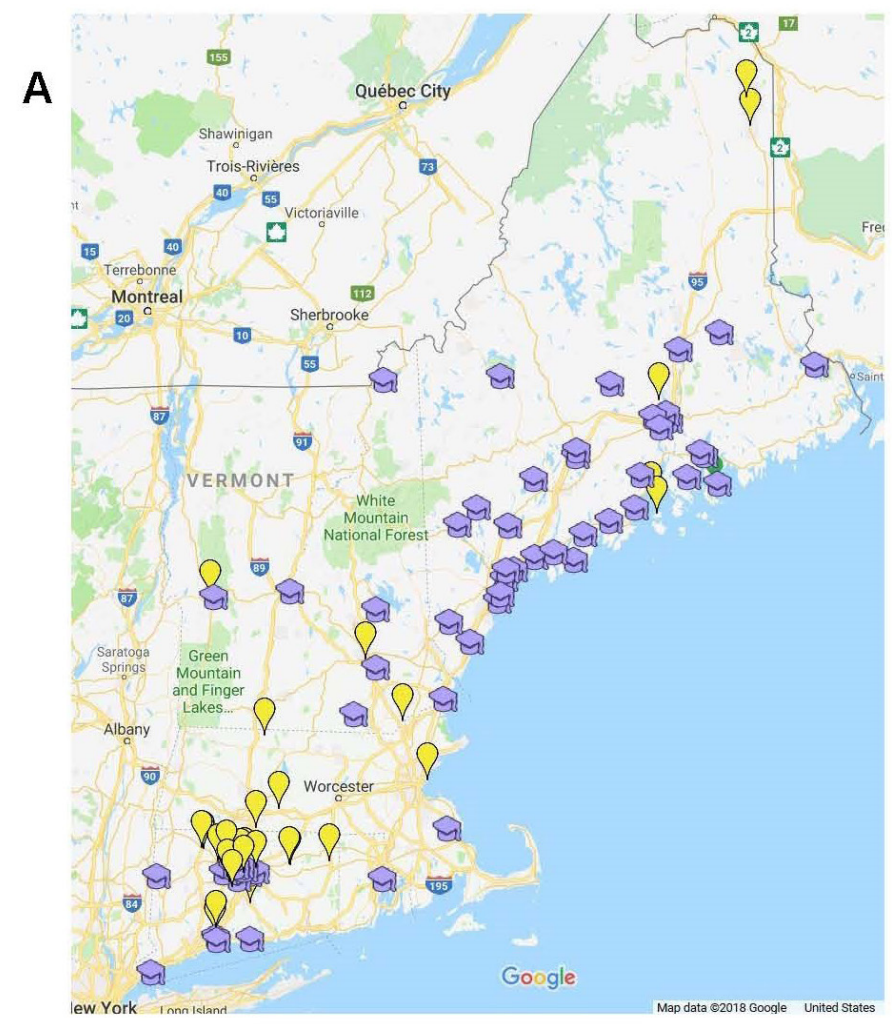

with basic genetics instruction, teachers' success and high scores are not surprising. Still, we were pleased to find that teachers had satisfactory incoming genetics knowledge, as it provided a solid foundation for discussion of more advanced genomics concepts and a focus on skill-building.

Post-course evaluation. Upon completion of the PD course, teachers completed a survey to assess satisfaction with instruction, again via Qualtrics ${ }^{\circledR}$. All respondents agreed or strongly agreed (on a 5 point Likert response scale) with the statement, Overall, I was satisfied with the quality of the instruction. While the teachers were satisfied, we wanted to understand their major outcomes of the course. We therefore posed three open ended responses: 1) Things I learned as a result of this course; 2) Specific content areas or techniques I plan to study further; and 3) Things I didn't entirely expect, but am pleased to have gained from this course. Participants were given the opportunity to provide up to three responses for each item and open responses were quantified in post-survey analysis.

We (K.L. and M.M.) generated item codes iteratively from theory and a reading of the data (Chi, 1997; Huberman and Miles, 2002). Initial codes reflected TtGG's core content and skills targets, including bioinformatics, bioethics, laboratory methods and techniques, and genetics/genomics
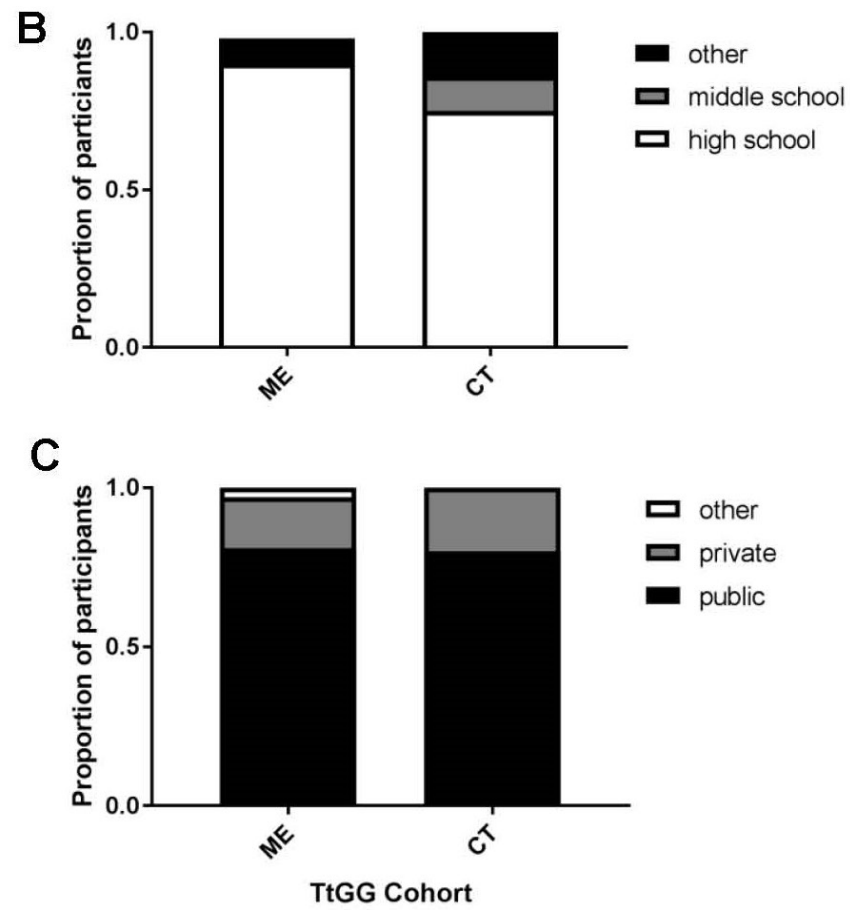

Figure 2. Location and demographics of TtGG participant school districts. A. Map of New England that captures a majority of teacher-participant locations. Mortar boards indicate academic year implementers. Pins indicate members that have participated in PD only at the time of map generation. Map was generated using Google Maps. For an up-to-date interactive map visit http://tinyurl.com/ttgg-map. Distribution of participants' school level (B) and school type (C) within PD course locations. 
content. A scan of the data suggested four additional codes were necessary to capture the full range of responses: instructional techniques, programmatic resources, networking, and personal growth. Two additional codes - ambiguous and other - were added to the scoring rubric to accommodate responses that couldn't be coded, or that did not fit the other codes, respectively (see Supplemental Table 1 for definitions of codes). The initial team then collaborated with two other team members to review the codes and assess interrater reliability. We coded two randomly-selected subsets of responses as a training exercise, and refined the code definitions. During this period, we established rules for defining a response's primary code from any additional codes. For example, responses such as "[I learned] how to better integrate bioinformatics into lessons" could be coded as bioinformatics and instructional techniques. In these cases, coders agreed to make the content or skills target the primary code (only primary codes are reported in this paper; secondary codes represent secondary learning responses scored during the evaluation). We then coded half of the remaining sample in pairs using the code definitions established in the second training round. We also recoded the responses from the first training round for consistency. Cohen's Kappa, a statistic which compares the agreement across raters against what would be expected by chance, varied by question (learned $\mathrm{k}=0.866, \mathrm{p}<.000$; study further $\mathrm{k}=0.847, \mathrm{p}<.000$; unexpected gain $\mathrm{k}=0.738, \mathrm{p}<.000$ ). All values were well above the 0.50 threshold recommended for acceptable consensus estimates of interrater reliability (Stemler and Tsai, 2008). We randomly selected one rater from each pair to be the primary rater, or rater of record for that round, and used that individual's ratings in the final analysis.

The top three things that teacher-participants learned ( $n=265$ responses from $n=91$ respondents) were laboratory methods and techniques $(28.7 \%$, e.g. "[I learned about] lab techniques and how they work"), bioethics (18.9\%, e.g. "[I learned about] the scary history of eugenics") and bioinformatics $(17.4 \%$, e.g. "[I learned] how to access genetic information on gene databases") (Figure 3A). The overwhelming frequency of learning laboratory methods and techniques reflects our observations during the course. Though teacher-participants are well prepared in their content knowledge, they are uncomfortable with molecular research equipment and lack confidence in the lab. We witnessed large gains in hands-on laboratory skills over the week-long PD course.

Respondents ( $\mathrm{n}=234$ responses from $\mathrm{n}=90$ respondents) indicated that the top three things they'd like to study further are bioinformatics $(29.5 \%$, e.g. "Genomic computing is beginning to be less fuzzy, but getting better with more practice"), genetics and genomics content $(26.9 \%$, e.g. "I need to understand more about specific genes we are being offered") and bioethics $(20.9 \%$, e.g. "[I need to study] cross disciplinary lessons incorporating bio ethics [sic]) (see Figure
3B). Considering our observations during the course, these data are not surprising. Even after several lessons in bioinformatics, online databases are still enigmatic to a majority of teachers. They are cautious to explore and prefer to know the direct path to find data rather than adopt an iterative or exploratory process of trial and error in database browsing. Additionally, in all three of these topics (molecular genet-

A

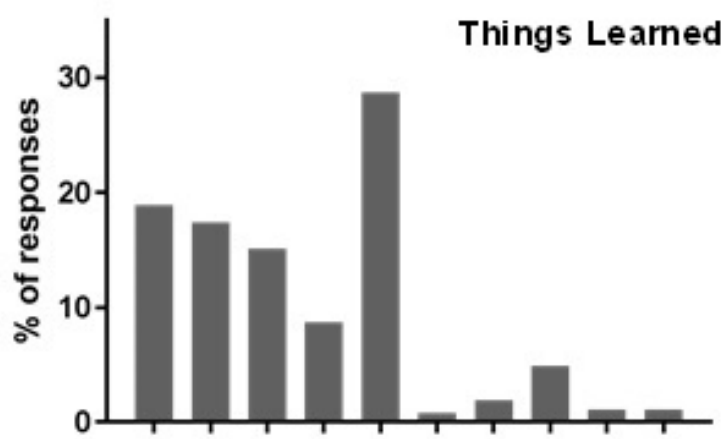

B

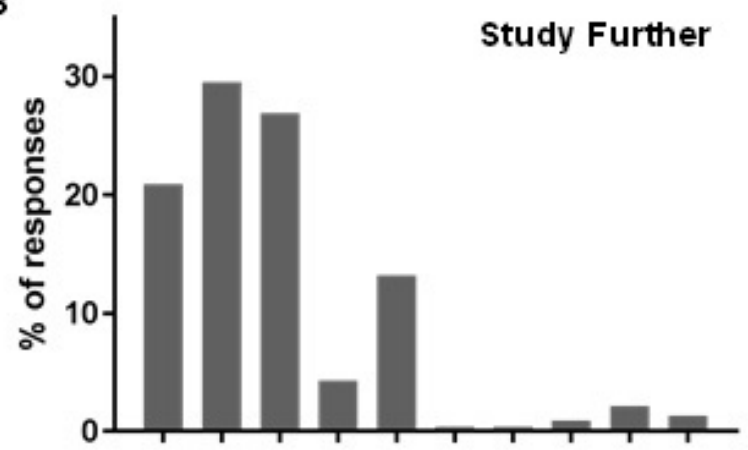

C

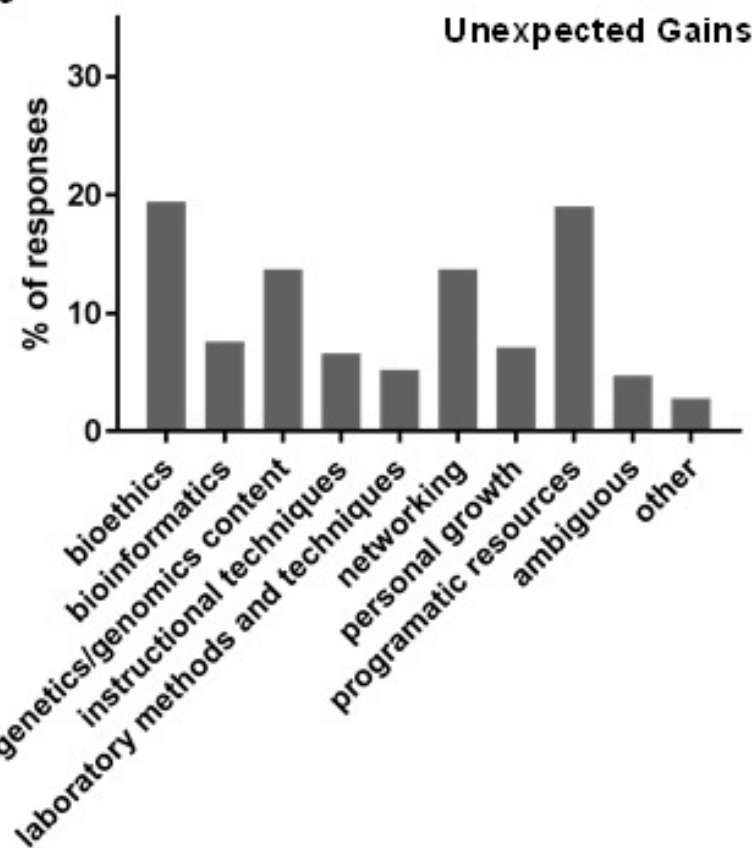

Figure 3. Coding of open ended responses on PD course evaluations of A) Things I learned as a result of this course, B) Specific content areas or techniques I plan to study further, and C) Things I didn't entirely expect, but am pleased to have gained from this course. 
ics, bioinformatics and ELSI), the plethora of available content exceeds what can be taught in a one week introductory course. We are thrilled to have given them enough information to prompt further independent investigation.

The top three unexpected gains $(\mathrm{n}=211$ responses from $\mathrm{n}=85$ respondents) were programmatic resources $(19.0 \%$, "I had no idea we were going to be given all kinds of advanced equipment to use in our classes. Amazing."), bioethics $(19.4 \%$, e.g. "I didn't expect to be so affected by the bioethics"), and a tie for genetics and genomics content (13.7\%, e.g. "[I was surprised] how much variance [sic] there is in the human genome.") and networking (13.7\%, e.g. "[I was surprised] I met a lot of great teachers with whom I can share experiences and ideas") (Figure 3C). Based upon feedback by teachers regarding other professional development experiences in the life sciences, it appears that the extent of academic year support offered by TtGG is unparalleled in the New England region. While an effort is made to highlight academic year support in all recruitment materials, it seems the reality of that promise does not manifest among participants until completion of the PD course.

During the courses, we have observed that participants in the Connecticut cohort tend to move more rapidly through laboratory sessions and absorb content more quickly allowing for conversations that extend beyond the standard TtGG PD curriculum. We were interested if these observations of apparent faster learning lead to differences in types of self-reported impacts of the PD course. We used a chi-square analysis to examine the frequency of each code between cohorts with a Bonferroni correction to guard against the possibility of obtaining a significant result by chance. This conservative test indicated that patterns of responses did not vary across program years or by cohort location (all $\mathrm{p}$ values $>.005$ ). While this was surprising based on our observations, these data demonstrate that teacher-participants from Maine and Connecticut are learning, exploring and finding unexpected value in the same areas. We interpret this to mean that TtGG is beneficial for all teacher-participants, whether they have been teaching advanced biology topics for years, or whether this is their first experience integrating molecular genetics into a high school laboratory.

TtGG Provides Enhancement to Existing Genetics Curricula. From the data above, this study demonstrates that the PD course is valuable to teachers; however, in order to begin assessing the second goal of the program (increased student understanding of genetics), it is essential that teachers' newfound knowledge and skills are passed on to students. Over the past three academic years (2014/15, 2015/16 and 2016/17), 75\% (60/80) of teacher-participants have implemented the TtGG lessons (Figure 2A). Teacher-participants were classified as implementers if they performed any arm of the program: laboratory molecular genetics, bioinformatics or bioethics. Note that data discussed in this section does not include teachers trained within the 2017 professional development cohort, whose implementations during the 2017/18 academic year were not complete during preparation of this manuscript.

Implementation rates. Over the past three years, first time implementation rates have been rising $(50 \%$ of 2014 cohort (8/16), $79 \%$ of 2015 cohorts (26/33), and $87 \%$ of 2016 cohorts (27/31)). Of the teachers who implemented TtGG following the 2014 and 2015 PD courses, 65\% (22/34) have completed a second implementation or more. One teacher (from an under-resourced public high school in rural Maine) performed four separate implementations (with AP, Honors and College Prep Biology classes) within two years. We attribute our success in implementation and retention rate to several factors: 1) we hired TtGG-dedicated staff members prior to the 2015-2016 academic year to support and manage classroom implementation; 2) in 2016, we began incentivizing implementation of the curriculum with a one-time $\$ 500$ stipend to offset the teacher's additional effort to implement TtGG lessons for the first time; and 3) we have increased teacher communication and interaction throughout the academic year, including regional teacher-participant meetups, participation in other regional high school teacher events and publication of a monthly program communique that highlights genomics and bioethics news. Anecdotally, teachers who did not implement have cited school administrative pressures in other areas, reassignment away from teaching biology, or relocation as reasons for not using TtGG lessons. However, as evidenced by our high implementation rates, these circumstances are rare.

Impact of implementation on students. Over 3,700 students across seven states have participated in a school-based TtGG lesson during the last three years. Of those students, nearly one third $(30 \%)$ were enrolled in a standard biology class (either introductory or college prep biology courses) (Figure 4). Approximately the same numbers of students were enrolled in Honors Biology (29\%) or advanced biology courses (24\%, including AP or biology electives). The nearly equal distribution of students across the three major tiers of high school biology instruction indicates that our modularized lessons and labs are appropriate for students at multiple levels. Our curricular elements will continue to reach more students year by year as we have committed to supporting every trained teacher for the duration of our program. The number of students who participate in TtGG during the 2017/18 academic year is on track to exceed 2016/17 participation by $25 \%$.

Since we promote teacher autonomy, we rely heavily on self-reported evaluation data to gain a view into TtGG classroom implementation. Over the last two academic years (2015/16 and 2016/17), 67 out of 85 implementing teachers have provided feedback about their experience through a post-implementation survey distributed using Qualtrics ${ }^{\circledR}$ 


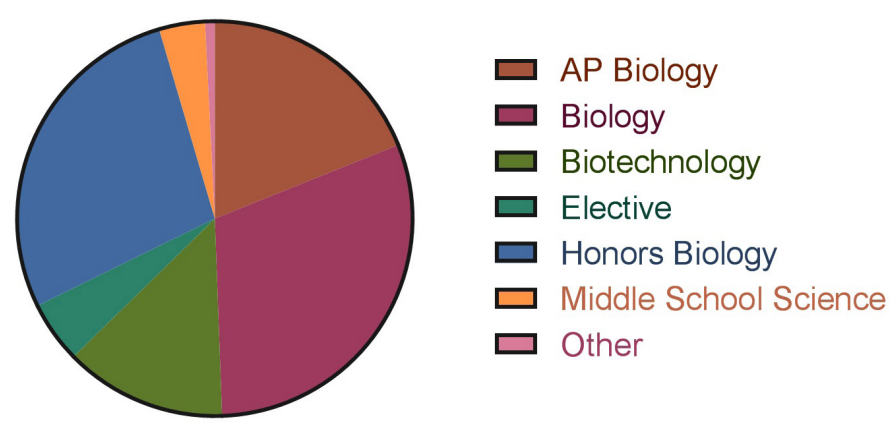

Figure 4. Distribution of students impacted by TtGG by biology class type. Data represents academic years 2015-2016 and 20162017, $n=3780$ students.

within six months of their implementation. All but one of the respondents (99\%) utilized the JAX-designed laboratory lessons and support; this teacher used only the bioethics lessons. Of the five genetic assays described in the TtGG curricula, most teachers $(74 \%, 63 / 85)$ chose to demonstrate genetic variation of the ACE gene (35/85 chose ACTN3, 28/85 chose OXTR, 17/86 chose CYP2C19, 7/85 chose TAS2R38 [only offered one academic year as a pilot]). Some teachers chose ACE due to the simplicity of the laboratory methods and its engaging association with muscle physiology and athletics. Other teachers started with an ACE lesson before allowing their students to perform more complicated techniques and sensitive assays on other genetic loci. On average, teachers implemented 1.8 gene assays per implementation. Over $85 \%$ of the respondents (58/67) also incorporated bioethics modules into their genetics unit (data was not collected on which ethics lessons were taught). Yet, fewer than half attempted to teach bioinformatics (31/67). Teachers cite limited class time as the reason for eliminating bioinformatics, stating either that other modules took priority, or unforeseen events such as snow days absorbed the time they intended to spend on this topic. In our opinion, bioinformatics is essential to genomics instruction, and this level of content and skills distribution is disappointing. We explore future directions and improvements for this arm of the program below. Taken together, these data demonstrate that teachers take advantage of the modularization of the TtGG program; they choose a variety of different pathways to meet the needs of their classroom. One size does not fit all.

In order to begin assessing the TtGG program impact on students, we evaluated one of the open-ended questions in the post-implementation teacher survey: What were the most important learning outcomes for your students during your implementation? Two team members engaged in the same process of code creation and interrater reliability described herein previously. They identified 123 outcomes across 62 respondents in the 2016 and 2017 cohorts. Cohen's Kappa was $0.775, \mathrm{p}<.000$, which is above the minimum 0.50 standard for acceptable interrater reliability. Supplemental Table 2 contains a full list of codes, definitions and results. The top three outcomes were genetics and genomics content $(20.3 \%$, e.g., "[The most important outcome was] students gaining a better appreciation for the central dogma of molecular biology..." ); hands-on experience (19.5\%, e.g., "They felt successful using the micropipettors, they was [sic] thrilled to see the centrifuges in action, and were gratified to use all of the equipment and supplies" ); and biotechnology, not otherwise specified $(11.3 \%$, e.g., "[The most important outcome was] the process of PCR and its importance"). This final category was created because raters observed a large portion of responses that mentioned biotechnology tools or methods but did not describe the depth of understanding required to be coded as theory, or use precise enough language to interpret as a skills-based outcome for coding as handson. While this code was slightly ambiguous, we believe that it still represents a beneficial experience of exposure to the field, if nothing else. While not in the top three, other interesting codes emerged from these responses such as following directions $(8.9 \%)$ and experience doing realistic science $(10.6 \%)$. Teachers found value in students having to read detailed protocols and execute the instructions with precision, a necessary but underutilized skill in an inquiry-based experimentation classroom. Teachers also feel that their students "just loved being exposed to an authentic experience" with scientific equipment and unknown results. What is most interesting to us is that none of the teachers mentioned bioinformatics as an important outcome. We explore this finding below. These teacher-reported student outcome data will help to inform development of research questions for future investigation of the impacts of the TtGG experience on students.

\section{THE FUTURE OF TEACHING THE GENOME GENERATION}

Improvements to Teacher and Student Bioinformatics

Education. From our data, it is clear that teachers enjoy and utilize the program's three-part framework connecting molecular genetics, bioinformatics, and ethics. However, the bioinformatics arm is significantly underutilized by teachers during the academic year; only half of our implementers taught lessons in bioinformatics and none of them view this topic area as an important student learning outcome. We view these bioinformatic skills as a prerequisite to future genomic investigations and feel it is essential to find a way to make bioinformatics more accessible to teachers. In the infancy of this program, bioinformatics was only suggested for more advanced learners. There was not an integrated lesson for our most popular, but most simplistic assay, genotyping ACE by post-PCR electrophoresis. Our future goal is to revise the bioinformatics exercises so that 1) exercises can be utilized in introductory classes and paired with the ACE laboratory procedures; 2) teachers have increased confidence to teach 
bioinformatics through practice during the PD course; 3) students get excited by bioinformatics through engagement in real-world case studies and; 4) bioinformatics lessons are better aligned to Next Generation Science Standards. We will look to other successful programs and methodologies (Magana et al., 2016) to ground our revised exercises in evidence-based practices. Through these enhancements to the curriculum, we hope to improve both teacher usability and student engagement in bioinformatics.

Empowering Successful Implementers. Because learning new material and skills in an intensive PD course can be intimidating for many of our teachers, we make every attempt to build strong social and professional networks within and across TtGG cohorts. During the PD courses we observed the development of both friendships and professional connections. On the other hand, as indicated in the 2015/16 post-implementation survey, teachers rarely capitalized on new-found connections; only 11 out of 28 respondents indicated that they had interacted with another TtGG participant during the subsequent school year. In response to these data, we initiated mid-year meet-ups to provide both continuing PD and another opportunity for peer interactions. In the 2016/17 post-implementation survey, 33 out of 41 respondents reported interacting with other TtGG teachers during the school year. We attribute this strengthening of professional networks to our recent network-building efforts and the sheer growth of our teacher community.

As learners encounter boundaries in their knowledge and experience, it has been shown that having a partner can alleviate both stress and negative self-perceptions (Wenger, 2000). Having a peer by their side can encourage teachers to attempt to better understand content beyond their perceived ability. With this in mind, we have admitted 17 teacher-pairs (teachers working together in the same school) into the PD program. This strategy appears to be succeeding with all but one of the teacher-pairs implementing the program (94\%), a higher implementation rate than the average. Additionally, many teachers are taking independent initiative to expand TtGG within their school; over $80 \%$ of implementing teachers (as reported in the 2016/17 post-implementation survey) have shared their experiences and knowledge with co-workers, demonstrating the importance and necessity of institutional backing. With this in mind, after each summer's PD courses, we communicate with teachers' administrators and department chairs and describe the program to foster continuing support for modern genetics education and adoption of TtGG.

We also seek to understand the impact of TtGG on individual teaching practices and on participants' self-efficacy in teaching genomics. We hypothesize that TtGG will increase hands-on learning and the relevance of genetics lessons to students. We will test this hypothesis by sampling and analyzing teachers' lesson plans, both pre- and post-profes- sional development. We also hypothesize that TtGG will increase teachers' self-efficacy at genetics instruction and will test this by developing TtGG-specific items administered in a retrospective pre- and post-test format. Anecdotally, we have observed that 'teachers don't know what they don't know' until after the professional development, thus justifying a retrospective pretest evaluation strategy (Lamb and Tschillard, 2005). Additionally, in order to better understand the practicalities of how teachers are using the TtGG lessons and labs in their classrooms, we will observe implementations at a subset of schools. We will pursue these more detailed assessments of teacher impacts in partnership with Rockman et al., an independent evaluation, research, and consulting firm.

\section{Translation of Teacher Professional Development to} Student Learning. Pending the expansion of TtGG cohorts across more schools and the introduction of more students to genomics education, we will evaluate the impact of TtGG curricula on student learning. We plan to recruit approximately 200 students who have completed TtGG genomics lessons in introductory biology and a similar number who have completed TtGG in AP Biology. Using content knowledge tests, we will compare these groups to an equal cohort of high school students who have not yet completed TtGG lessons, but will in a future year. In this way, we will gain insight into the educational efficacy of our hands-on, participatory model of genomics education versus textbook or classroom based genetics instruction.

\section{CONCLUSION}

Our high school teacher professional development program in human genetics and genomics, Teaching the Genome Generation, has proven to be a desirable and successful program in New England. With 111 teachers trained thus far, and adding more each year, it is not unreasonable to expect that TtGG will reach over 5,000 students per year with our current, modularized and customizable lessons. Through the built-in flexibility of our program, that we have shown to be compatible with a myriad of classroom formats, and our practice of robust communication and classroom support, TtGG is enhancing genetics and genomics instruction. As TtGG matures, we expect to introduce the program to more New England high schools, expand to Sacramento, California in 2018 (site of a third JAX facility), and make our lesson materials accessible to teachers nationwide through online and digital education. Through these efforts, we seek to transform high school genetics education so that current and future generations have a reason to celebrate genetic diversity and have an informed and empowered voice in personal genetic health decisions. For more information about the program or to gain access to our curriculum materials please contact ttgg@jax.org. 


\section{AUTHOR INFORMATION}

\section{Author Contributions}

The manuscript was written through contributions of all authors. All authors have given approval to the final version of the manuscript.

\section{FUNDING SOURCES}

This work is funded by an NIH SEPA Award (R25GM129169). Program development was funded by grant awards from Jane's Trust, the Arthur Vining Davis Foundations, and the Petit Family Foundation. The TtGG program could not be accomplished without the help of numerous expert teachers across New England; the authors greatly appreciate significant contributions made by Barbara Farrell, Stephanie Dumont, and Laura Butterfield. Dana Waring and Marnie Gelbart at pgEd have provided expert ethics guidance or instruction each year. Ashley Greaves, a summer student funded through the Maine INBRE program (P20GM103423), developed and optimized the TAS2R38 assay.

\section{ACKNOWLEDGMENTS}

School year implementations would not be possible without the support of Alison Kieffer and Sarah Wojiski at The Jackson Laboratory.

\section{ABBREVIATIONS}

Teaching the Genome Generation: (TtGG); PD: Professional development; JAX: Jackson Laboratory; SEPA: Science Education Partnership Award; pgEd: Personal Genetics Education Project; ELSI: Ethical, legal and social issues; NGSS: Next Generation Science Standards; PCR: Polymerase chain reaction; ACE: Angiotensin converting enzyme; OXTR: Oxytocin receptor; CYP2C19: Cytochrome P450; ACTN3: $\alpha$-actinin 3; TAS2R38: Taste receptor 2

\section{REFERENCES}

Bowling, B.V., Acra, E.E., Wang, L., Myers, M.F., Dean, G.E., Markle, G.C., Moskalik, C.L., and Huether, C.A. (2008). Development and evaluation of a genetics, literacy assessment instrument for undergraduates. Genetics. 178, 15-22.

Chi, M. (1997). Quantifying qualitative analyses of verbal data: A practical guide. Journal of the Learning Sciences, 6(3), 271-315.

Garber, K.B., Hyland, K.M., and Dasgupta, S. (2016). Participatory genomic testing as an educational experience. Trends in Genetics, 32(6), 317-20.
Goldstein. J.A., and Blaisdell, J. (1996). Genetic tests which identify the principal defects in CYP2C19 responsible for the polymorphism in mephenytoin metabolism. Methods in Enzymology, 272, 210-8.

Green, E.D., and Guyer, M.S. (2011). Charting a course for genomic medicine from base pairs to bedside. Nature, 470(7333), 204-13.

Huberman, A. M. and Miles, M. B. (2002). The qualitative researchers' companion. Thousand Oaks, CA: Sage.

Kim, U., Jorgenson, E., Coon, H., Leppert, M., Risch, N., and Drayna, D. (2003). Positional cloning of the human quantitative trait locus underlying taste sensitivity to phenylthiocarbamide. Science, 299(5610), 1221-1225.

Kumsta, R., and Heinrichs, M. (2013). Oxytocin, stress and social behavior: Neurogenetics of the human oxytocin system. Current Opinions in Neurobiology, 23,11-16.

Lamb, T. A., and Tschillard, R. (2005). Evaluating learning in professional development workshops: Using the retrospective pretest. The Journal of Research in Professional Learning. Retrieved from http://nsdc.org/library/publications/ research/lowden.pdf

Magana, A.J., Taleyarkhan, M., Alvarado, D.R., Kane, M., Springer, J., and Clase, K. (2016). A survey of scholarly literature describing the field of bioinformatics education and bioinformatics educational research. CBE Life Sciences Education, 13, 607-623.

Maltese, A. V., and Tai, R.H. (2010). Pipeline persistence: Examining the association of educational experiences with earned degrees in STEM among U.S. students. Science Education Policy, 95(5), 877-907.

Middleton, A., Morley, K.I., Bragin, E., Firth, H.V., Hurles, M.E., Wright, C.F., and Parker, M. (2015). Attitudes of nearly 7000 health professionals, genomic researchers and publics toward the return of incidental results from sequencing research. European Journal of Human Genetics, 24(1), 2129.

Moreno, N. (2005). Science education partnerships: Being realistic about meeting expectations. Cell Biology Education, $4,30-32$.

Putheucheary, Z., Skipworth, J.R.A., Rawal, J., Loosemore, M., Van Someren, K., Montgomery, H.E. (2001). The ACE gene and human performance: 12 years on. Sports Medicine, 41(6), 433-448.

Salari, K., Karczewski, K.J., Hudgins, L., and Oromond, K.E. (2013). Evidence that personal genome testing enhances student learning in a course on genomics and personalized medicine. PLOS One, 8(7).

Stemler S. E., and Tsai, J. (2008). Best practice in interrater reliability: Three common approaches. In Osborne J. W. (Ed.), Best Practices in Quantitative Methods (pp. 29-49). Los Angeles, CA: SAGE Publications.

Weber, K.S., Jensen, J.L., and Johnson, S.M. (2015). Anticipation of personal genomics data enhances interest and learning environment in genomics and molecular biology undergraduate courses. PLOS One, 10(8).

Wenger, E. (2000). Communities of practice and social learning systems. Organization. 7(2), 225-46. 
Wray, C. (2017). Introducing students to the genome: Brave new world or the Red Queen's Wonderland? The American Biology Teacher, 79(4), 253.

Yang, N., MacArthur, D.G., Gulbin, J.P., Hahn, A.G., Beggs, A.H., Easteal, S., and North, K. (2003). ACTN3 genotype is associated with human elite athletic performance. American Journal of Human Genetics, 73(3), 627-631 